\title{
How Very-Long-Chain Fatty Acids Could Signal Stressful Conditions in Plants?
}

\author{
Antoine De Bigault Du Granrut ${ }^{1}$ and Jean-Luc Cacas ${ }^{1,2 *}$ \\ ' UMR1318 Institut National de la Recherche Agronomique-AgroParisTech, Centre Institut National de la Recherche \\ Agronomique de Versailles-Grignon, Institut Jean-Pierre Bourgin, Versailles, France, ${ }^{2}$ Département Sciences de la Vie et \\ Santé, AgroParisTech, UFR de Physiologie Végétale, Paris, France
}

OPEN ACCESS

Edited by:

Sylvain Jeandroz, Agrosup Dijon, France

Reviewed by:

Christina Kuehn, Humboldt University of Berlin, Germany

Susanne Hoffmann-Benning, Michigan State University, USA

*Correspondence: Jean-Luc Cacas jean-luc.cacas@agroparistech.fr; cacasj|@yahoo.fr

Specialty section: This article was submitted to Plant Physiology, a section of the journal Frontiers in Plant Science

Received: 02 July 2016 Accepted: 20 September 2016 Published: 18 October 2016

Citation:

De Bigault Du Granrut A and Cacas J-L (2016) How Very-Long-Chain Fatty Acids Could Signal Stressful Conditions in Plants?

Front. Plant Sci. 7:1490. doi: 10.3389/fpls.2016.01490
Although encountered in minor amounts in plant cells, very-long-chain fatty acids exert crucial functions in developmental processes. When their levels are perturbed by means of genetic approaches, marked phenotypic consequences that range from severe growth retardation to embryo lethality was indeed reported. More recently, a growing body of findings has also accumulated that points to a potential role for these lipids as signals in governing both biotic and abiotic stress outcomes. In the present work, we discuss the latter theory and explore the ins and outs of very-long-chain fatty acid-based signaling in response to stress, with an attempt to reconcile two supposedly antagonistic parameters: the insoluble nature of fatty acids and their signaling function. To explain this apparent dilemma, we provide new interpretations of pre-existing data based on the fact that sphingolipids are the main reservoir of very-long-chain fatty acids in leaves. Thus, three non-exclusive, molecular scenarii that involve these lipids as membrane-embedded and free entities are proposed.

Keywords: very-long-chain fatty acids, biotic and abiotic stress, signaling cascades, sphingolipids, membrane microdomains, plasma membrane, endoplasmic reticulum, secretory pathway

\section{INTRODUCTION}

Both abiotic and biotic stresses, as well as developmental cues, have long been known to drastically modify lipid composition-including fatty acid (FA) content-at the organ level. For instance, it is well-documented that phosphate starvation reorients lipid anabolism from phospholipid toward galactolipid synthesis (Kobayashi et al., 2006), likely for maintaining plant cell homeostasis until the constraint is relieved. Likewise, temperature-induced stress provokes changes in plasma membrane (PM) physico-chemical properties due to modification of sterol concentration and FA double bond index (Los and Murata, 2004). Progressive loss of chloroplast galactolipids is also a well-defined hallmark of foliar senescence processes (Jia and Li, 2015). Furthermore, plant resistance to pathogens can cause the consumption of chloroplast-originating polyunsaturated fatty acids for supplying an oxidative pathway that orchestrates host cell dismantling (Cacas et al., 2005). Obviously, all these events, whether or not associated with stress acclimation, are relevant to profound structural alterations and mobilize huge amounts of lipids that can be readily quantified by regular biochemical methods. By contrast, one can easily imagine that lipidcontingent signaling events relies on more subtle changes. This is perfectly illustrated by the case of phosphatidic acid, a conserved stress signaling molecule produced by either phospholipase $\mathrm{D}$ or the coordinated action of phospholipase C and diacylglycerol kinase (Guo et al., 2011). Because of its low abundance, phosphatidic acid is commonly evidenced by in vivo isotopic labeling experiments 
(Arisz et al., 2009; Cacas et al., 2016a). Another example that could be cited is that of the FA-derived hormonal signal jasmonic acid that requires highly sensitive liquid chromatography-based methods for efficient quantification (Glauser and Wolfender, 2013; Cacas et al., 2016b). Additionally, to the best of our knowledge, marked degradation of the respective lipid substrates alimenting the two latter signaling cascades were rarely correlated with signal generation. Hence, this hints the importance of carefully considering, whenever possible, absolute concentrations of metabolites involved when discriminating among signaling events and structural changes. What about very-long-chain fatty acids (VLCFA)? How are they synthesized? And, how their levels are affected in response to stress?

\section{BIOSYNTHESIS OF VERY-LONG-CHAIN FATTY ACIDS IN PLANT CELLS}

In plants, lipid metabolism is highly compartmentalized and this intricate organellar networks allows fine-tuned regulation of the intracellular catabolic/anabolic balance for approximately several thousands of molecular lipid species. Biosynthesis of FA-containing lipids-mostly phospholipids, galactolipids, sphingolipids, triacylglycerides, and to a lesser extent, acylsterylglycosides-relies on two interacting metabolic routes: the "prokaryotic pathway" that resides in plastids and the "eukaryotic pathway" that is localized to endoplasmic reticulum (ER). Basically, production of FA-building units is initiated in plastids by the fatty acid synthase (FAS) complex II that uses malonylCoA and acetyl-CoA as co-substrates and NADPH as reductant. Each FAS-mediated cycle adds 2 carbons to acyl-CoA chains until molecules reaches a length of 16 or 18 carbons. Combined thioesterase and acyl-CoA synthetase activities are then invoked in active export of aliphatic chains from stroma to cytoplasm, where this pool of activated molecules is used by the ER for further chain length extension (Li-Beisson et al., 2010).

Very-long-chain fatty acids, formally defined as FA longer than 18 carbons, are extended by an ER membrane-embedded protein complex of 4 enzymes, acting presumably on the cytosolic side (see Haslam and Kunst, 2013 for an updated review). Fatty acid elongase activity results in successive action of $\beta$-ketoacyl-CoA synthase (KCS), $\beta$-ketoacyl-CoA reductase (KCR), $\beta$-hydroxyacyl-CoA dehydratase (HCD), and enoyl-CoA

\footnotetext{
Abbreviations: ACBP, Acyl-CoA Binding Protein; ACD5/11, ACCELERATED CELL DEATH 5/11; BI1, BAX INHIBITOR 1; Cer, ceramide; Cer-P, ceramide phosphate; CerS, ceramide synthase; CoA, coenzyme A; DIM, detergent-insoluble membranes; ECR, enoyl-CoA reductase; EIX2, ETHYLENE-INDUCING XYLANASE 2; ER, endoplasmic reticulum; ES, endomembrane system; FAH1, fatty acid hydroxylase 1; FFAR/GPAR, FREE FATTY ACID RECEPTORS/G PROTEIN-COUPLED RECEPTORS; FA, fatty acid; FAH, fatty acid hydroxylase; FAS, fatty acid synthase; GA, Golgi apparatus; GFP, green fluorescent protein; GIPC, glycosyl-inositolphosphoryl-ceramide; GluCer, glucosylceramide; HCD, hydroxyacyl-CoA dehydratase; (h)VLCFA, (2-hydoxy-)very-long-chain fatty acid; IPCS, inositolphosphoryl-ceramide synthase; KCR, $\beta$-ketoacyl-CoA reductase; KCS, $\beta$-ketoacyl-CoA synthase; LCB, long-chain base; LCB-P, long-chain base phosphate; LOH, LAG ONE HOMOLOG; MPK6, MITOGEN-ACTIVATED PROTEIN KINASE 6; NADPH, Nicotinamide Adénine Dinucléotide Phosphate; PM, plasma membrane; PR1, PATHOGENESIS-RELATED 1; SPT, serine-palmitoyl-CoA transferase; TGN, trans-Golgi network.
}

reductase (ECR). Each of these enzymes utilizes as substrate the product of the previous one in cycles beginning by malonylCoA condensation to long-chain acyl-CoA (Figure 1). Except for ECR, which is a single copy-encoded gene in Arabidopsis thaliana, a huge multigenic family composed of 21 members codes for tissue-specific KCS enzymes (Joubès et al., 2008) that are thought to dictate the length of acyl-CoA chains produced by the complex (Fehling and Mukherjee, 1991; Millar and Kunst, 1997). Both KCR and HCD are encoded by 2 independent genes, dubbed KCS1/KCS2 and PASTICCINO2/PTPLA, respectively (Table 1). Such a complexity could suggest that multiple elongase complexes, which differ by their relative composition, coexist in ER membranes. In other words, functionally spatializeddomains with large metabolon units could orient the lipid class into which very-long-acyl chains are incorporated. But, only indirect evidence for this kind of ER sub-compartmentation were reported so far (Shockey et al., 2006). VLCFA are mainly present in the impermeable cuticular wax layer deposited at the plant aerial organ surface, in triacylglycerides found in seed oil and in sphingolipids, which act as structural elements in lipid bilayers forming endomembranes and PM (Bach and Faure, 2010).

\section{CHANGES IN VERY-LONG-CHAIN FATTY ACID LEVELS IN PLANT CELLS UNDERGOING STRESS}

With respect to modifications of VLCFA concentrations under stressful conditions, sparse data have been obtained but clear trends are currently emerging (Table 2). Overall, numerous abiotic constraints (salt, cold, hypoxia, heavy metal exposure...) were reported to increase VLCFA contents in distinct plant species. Induced Arabidopsis resistance to bacterial pathogens seems also associated with an augmentation of endogenous VLCFA levels (Raffaele et al., 2008). Not surprisingly, detailed lipid analysis revealed that VLCFA, which are both components and precursors of epicuticular wax, are affected by drought stress and bacterial infection in proportions which are clearly relevant to structural changes (Raffaele et al., 2008; Zhu and Xiong, 2013). This experimental fact makes full sense as cuticle is involved in limiting stomata-independent evaporation in shoots, suggesting a reinforcement of this hydrophobic layer under water stress. In the context of pathogen invasion, strengthening the apoplastic barrier is also a well-known defense phenomenon (Garcion et al., 2014), believed to prevent further micro-organism penetration and spreading.

Pioneering works pointed out the transcriptional activation of genes coding for members of the Arabidopsis ER-localized elongase complex in response to stress. It has been demonstrated that multiple KCS-encoding genes were responsive to light conditions, dehydration, salt, cold, and osmotic stresses (Joubès et al., 2008). Mutants deficient for the transcription factor MYB30 were proven to be unable to accumulate WT levels of VLCFA under hypoxia (Xie et al., 2015). In addition, microarray experiments showed that 3 out of the 21 KCS genes (KCS1, KCS2, and KCS10), one HCD gene (PASTICCINO 2) 


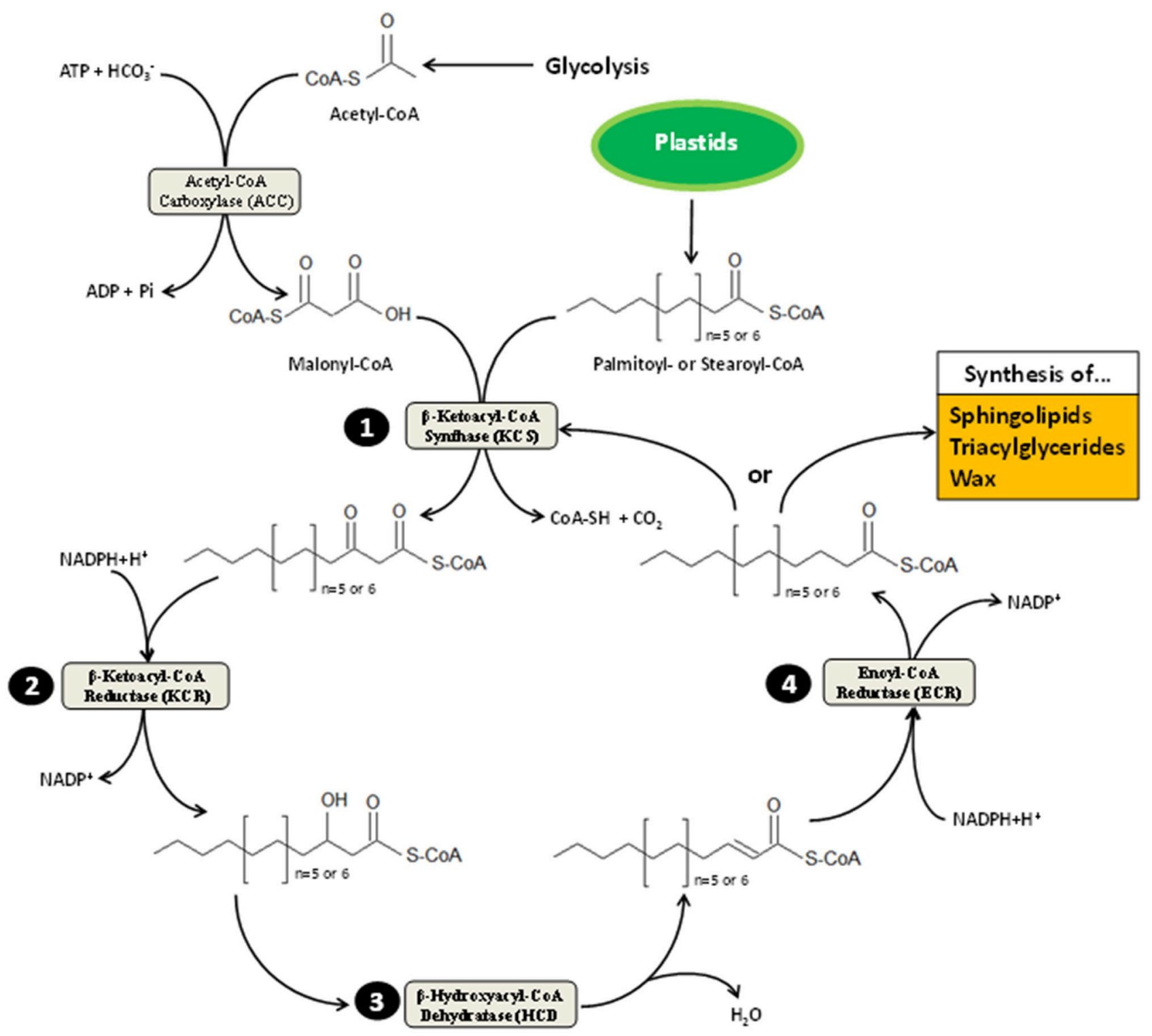

FIGURE 1 | Scheme representation of very-long-chain fatty acid elongation. This process takes place on cytosolic side of the ER membrane. It is alimented by acetyl-CoA and acyl-CoA originating from the cytoplasm-located glycolysis and plastid-resident FA elongation pathway, respectively. Plastids provides 16 or 18 carbon-long acyl-CoA (i.e., palmitoyl- and stearoyl-CoA) to be elongated. The first committed step to VLCFA elongation cycle is catalyzed by the $\beta$-ketoacyl-CoA synthase (KCS), which condenses malonyl-CoA (synthesized by carboxylation of acetyl-CoA moieties) with palmitoyl- or stearoyl-CoA. Resulting products are then reduced into $\beta$-hydroxacyl-CoA (step 2) before losing a molecule of water (step 3); the latter reaction of which is mediated by the $\beta$-hydroxacyl-CoA dehydratase (HCD). Upon dehydration, $\beta$-enoyl-CoA undergo reduction (step 4), forming acyl-CoA that harbor two additional carbons. These products can either be oriented toward sphingolipid, wax and triacylglyceride synthesis depending on tissue specificity and cell requirement or reenter VLCFA elongation cycle until its length reaches 28 carbons in Arabidopsis or more in other plant species. Each cycle turn consumes one molecule of ATP and two of NADPH $+\mathrm{H}^{+}$.

and the only ECR gene (CER10) were transcriptionally upregulated during incompatible interaction with bacteria, and the consecutive increase in VLCFA levels was confirmed by biochemical approach. This transcriptional reprogramming was further shown to be under the control of MYB30 (Raffaele et al., 2008). Although elongase regulation could account for cuticle structure readjustment, one cannot rule out the possibility that it could reflect an unusual context where VLCFA-contingent changes hide signaling cascades. Arguing in favor of this idea are several lines of evidence. Firstly, concentrations of VLCFA mobilized in many instances described in the literature are all the more sufficient for signaling purposes (Table 2). Secondly, except for drought stress (Zhu and Xiong, 2013), no data can currently explain clearly the role of VLCFA in certain specific abiotic contexts (like cold stress, mechanical injury and others) by the solely bias of cuticle. Thirdly, other lipids than wax components, such as complex sphingolipids that are potential reservoirs of signal molecules (Gronnier et al., 2016), exhibit 
TABLE 1 | Nomenclature of the VLCFA elongase complex-encoding genes.

\begin{tabular}{|c|c|c|c|c|c|c|}
\hline Gene names & Other gene names & Loci (AGI) & Protein activity & Protein length (aa) & M.W. (kDa) & pl \\
\hline KCS1 & - & At1g01120 & $\begin{array}{l}\beta \text {-ketoacyl-CoA synthase (catalyzes the first } \\
\text { committed step to VLCFA synthesis) }\end{array}$ & 528 & 59.28 & 8.9 \\
\hline KCS3 & - & At1g07720 & & 478 & 54.33 & 9.5 \\
\hline KCS4 & - & At1g19440 & & 516 & 57.84 & 9.1 \\
\hline KCS5 & CER60 & At1g25450 & & 492 & 55.65 & 8.9 \\
\hline KCS7 & - & At1g71160 & & 460 & 51.50 & 8.3 \\
\hline KCS8 & - & At2g15090 & & 481 & 54.19 & 9.4 \\
\hline KCS9 & - & At2g16280 & & 512 & 57.97 & 9.4 \\
\hline KCS10 & $F D H$ & At2g26250 & & 550 & 61.96 & 9.3 \\
\hline KCS11 & - & At2g26640 & & 509 & 57.81 & 9.6 \\
\hline KCS12 & - & At2g28630 & & 476 & 53.97 & 9.0 \\
\hline KCS16 & - & At4g34250 & & 493 & 55.78 & 9.1 \\
\hline KCS17 & - & At4g34510 & & 487 & 54.91 & 9.7 \\
\hline KCS18 & FAE1 & At4g34520 & & 506 & 56.26 & 9.8 \\
\hline KCS19 & - & At5g04530 & & 464 & 52.61 & 8.6 \\
\hline KCS2O & - & At5g43760 & & 529 & 59.31 & 9.2 \\
\hline KCS21 & - & At5g49070 & & 464 & 52.56 & 9.3 \\
\hline KCR1 & - & At1g67730 & ketoacyl-CoA reductase & 318 & 35.76 & 9.9 \\
\hline KCR2 & - & At1g24470 & & 312 & 35.00 & 9.8 \\
\hline$H C D$ & PAS2 & At5g10480 & $\beta$-hydroxyacyl-CoA dehydratase & 230 & 26.41 & 9.7 \\
\hline PTPLA & - & At5g59770 & & 272 & 30.96 & 10 \\
\hline
\end{tabular}

This table provides information on regular gene names, additional designations found in the literature and referenced loci based on the Arabidopsis Genome Initiative (AGI). Demonstrated or potential enzymatic activities of the corresponding proteins are also indicated. Protein length is expressed as the number of amino acids (aa). M.W. and pl refers to molecular weight and isoelectric point, respectively. Most data were retrieved from The Arabidopsis Information Resource (TAIR) website (https://www.arabidopsis.org/) and crossed with the Arabidopsis book chapter dedicated to acyl-lipid metabolism (Li-Beisson et al., 2010). Abbreviations: CER6, 10 and 60, ECERIFERUM 6, 10 and 60; CUT1, CUTICULAR 1; FAE1, FATTY ACID ELONGATION 1; FDH, FIDDLEHEAD; GLH6, GLASSY HAIR 6; HIC, HIGH CARBON DIOXIDE; PAS2, PASTICCINO 2; POP1, POLLEN-PISTIL INCOMPATIBILITY 1; PTPLA, PROTEIN-TYROSINE PHOSPHATASE-LIKE.

significant changes in their VLCFA contents following stress (Table 2). Lastly, transgenic lines that displayed VLCFA overaccumulation correlated with enhanced pathogen-contingent cell death phenotype (Raffaele et al., 2008). Given that cuticle-related processes are unlikely to control programmed cell death, it must be envisaged that VLCFA exert their putative effects on cell fate in an alternative manner. Thus, it seems reasonable to investigate the concept that VLCFA could participate to stress signaling pathway.

\section{ARE FREE VERY-LONG-CHAIN FATTY ACIDS GENUINE SIGNALING MOLECULES?}

In humans, lipid homeostasis is tightly controlled, and its long-term perturbation can have severe deleterious effects on health. Free FA contribute to the regulation of organ and tissue homeostasis by acting as signaling molecules through autocrine or paracrine cell non-autonomous modes. Extracellular free FA concentrations can be finely perceived by plasma membrane-localized protein receptors that discriminate among chain lengths. These are named FREE FATTY ACID RECEPTORS (FFAR)/G PROTEIN-COUPLED RECEPTORS (GPAR) (Ichimura et al., 2014). In plant genomes, no genes coding for such orthologous receptors could be retrieved by sequence comparison (unpublished data). Besides, even when a number of long-chain acyl-CoA binding proteins (ACBP) were reported to participate in plant stress tolerance (Xiao and Chye, 2011), it seems that they rather function as general regulators of lipid metabolism than as cognate signaling partners of acyl chains in challenged cells. For instance, AtACBP2 and AtACBP4 were found to physically interact with an ethylene-responsive transcription factor (Li and Chye, 2004; Li et al., 2008), possibly controlling by this means lipid-related gene expression. Another issue for VLCFA to be considered as genuine signals relies on 
TABLE 2 | Changes in VLCFA levels under stressful conditions.

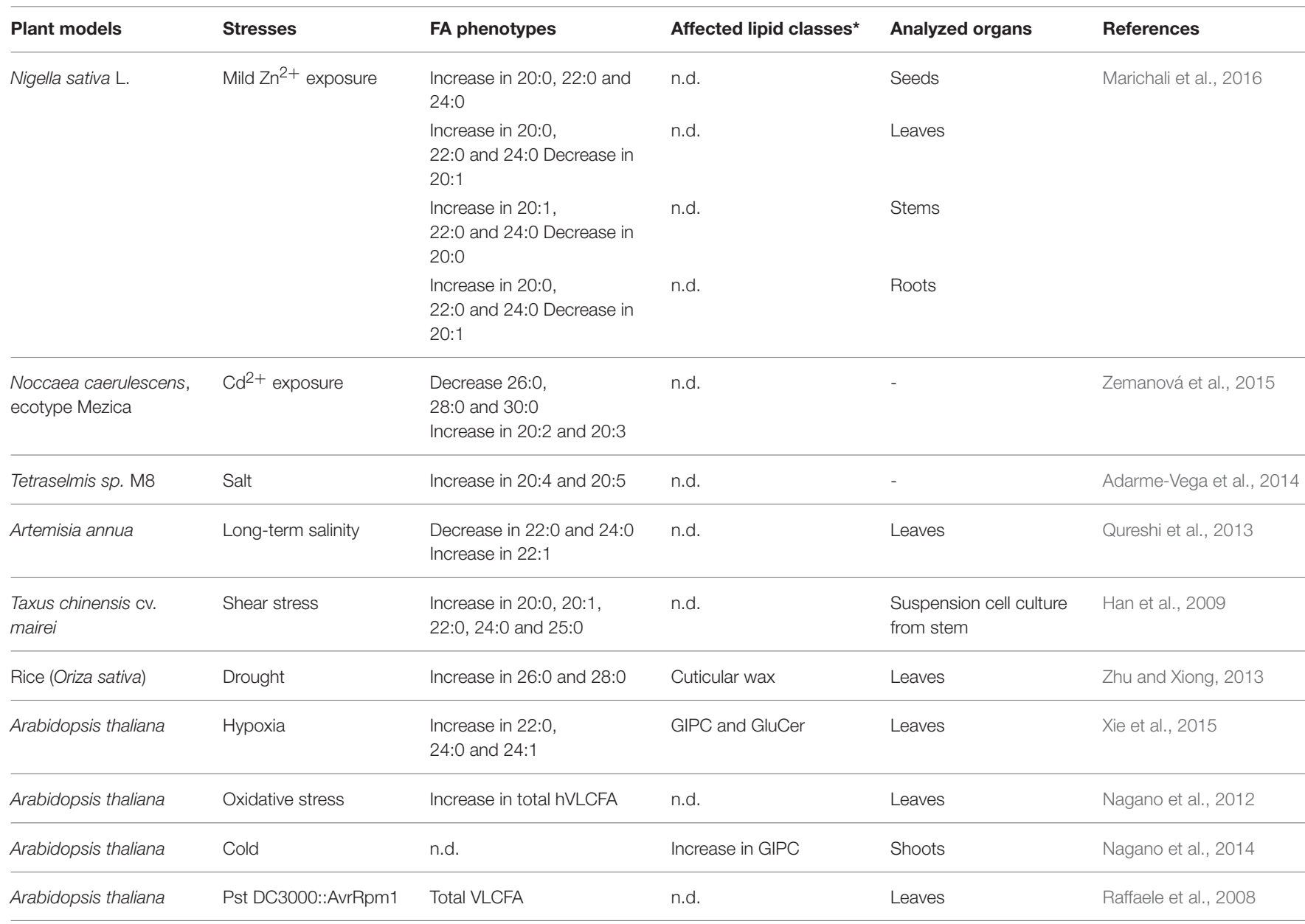

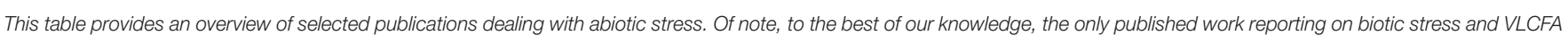

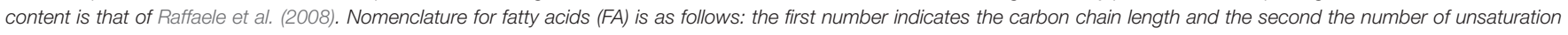

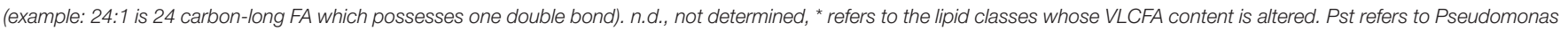
syringae $\mathrm{pv}$. tomato.

their amphipathic nature that renders them strong membrane destabilizers and not prone to cross lipid bilayers. This certainly prevents unmodified VLCFA from functioning as soluble signals at both the intra-and extra-cellular levels. Therefore, alternative hypotheses must be imagined for explaining how these lipids could regulate plant stress responses. What could be the molecular mechanisms invoked? Based on the literature, three potentially interconnected scenarii taking into account the observed relatively high amounts of VLCFA mobilized during stress response are described hereafter.

\section{"THE INDIRECT SPHINGOLIPID SIGNALING HYPOTHESES"-HOW TO RECONCILE VERY-LONG-CHAIN FATTY ACIDS WITH STRESS SIGNALING?}

Plant sphingolipids encompass four major classes: long-chain bases (LCB), ceramides (Cer), glucosylceramides (GluCer), and more complex glycosylated sphingolipids, known as glycosylinositolphosphoryl-ceramides (GIPC) (Figure 2A). Apart from GIPC, the synthesis of which is initiated in the ER and completed in the Golgi apparatus (GA), the three other classes are produced in the ER (Figure 2B). Neo-synthesis of LCB results from the condensation of serine and palmitoyl-CoA moieties catalyzed by a protein complex, so-called the serine-palmitoyl-CoA transferase (SPT). Subsequent reduction of the SPT product results in the synthesis of sphinganine, the precursor of the eight other LCB found in plants. Ceramide synthases (CerS), encoded by a multigenic family named after the yeast protein LAG ONE HOMOLOG (LOH), are responsible for the formation of the amide bond that links (V)LCFA to LCB, leading to Cer formation. Ceramides can then be used as backbone for the production of GluCer and GIPC by addition of a glucose molecule or an inositolphosphoryl group followed by one or several glycosylation steps, respectively (Markham et al., 2013). Noteworthy, it can be inferred, on the basis of their biosynthetic pathway (Li-Beisson et al., 2010), and additional data (Pata 
A

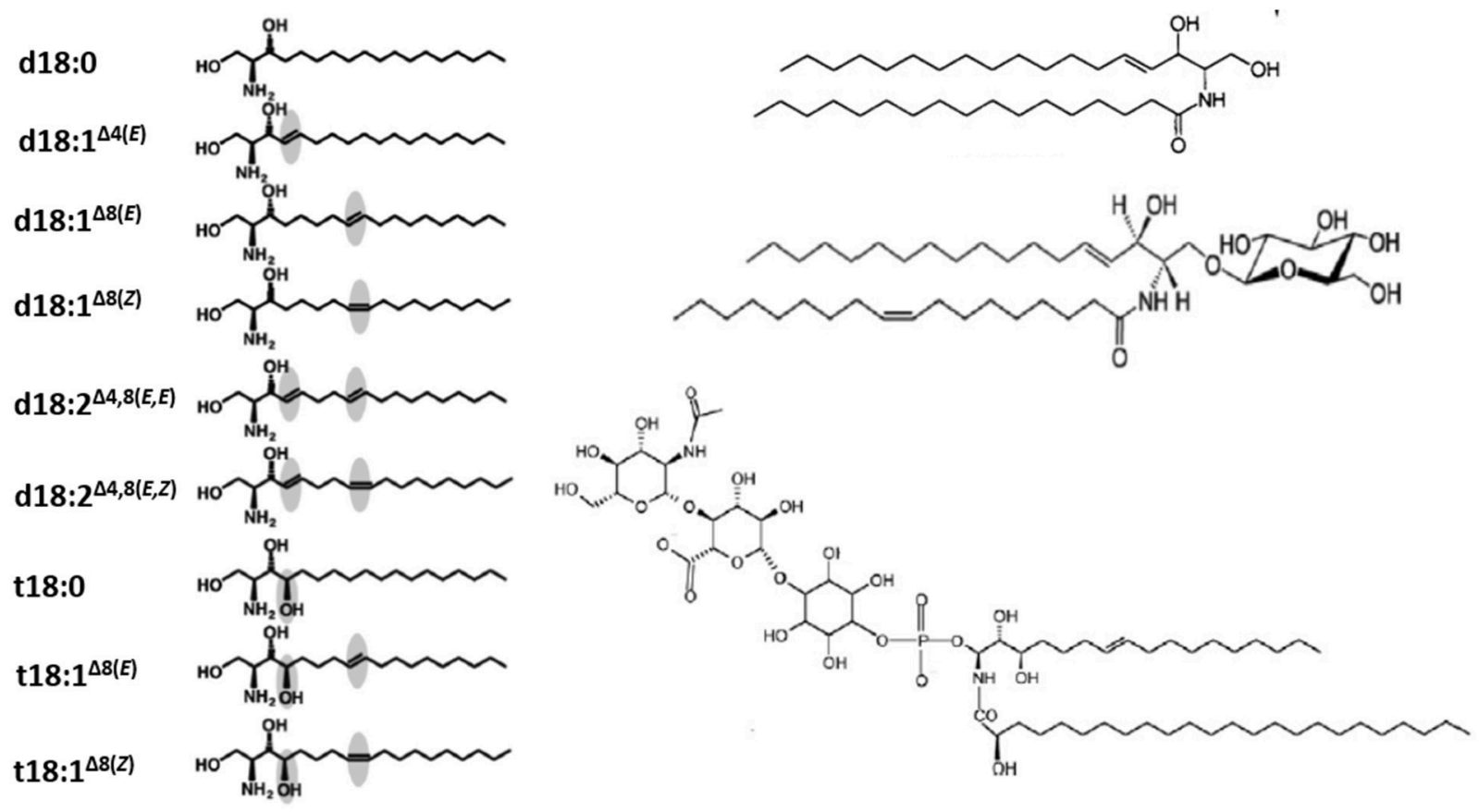

B

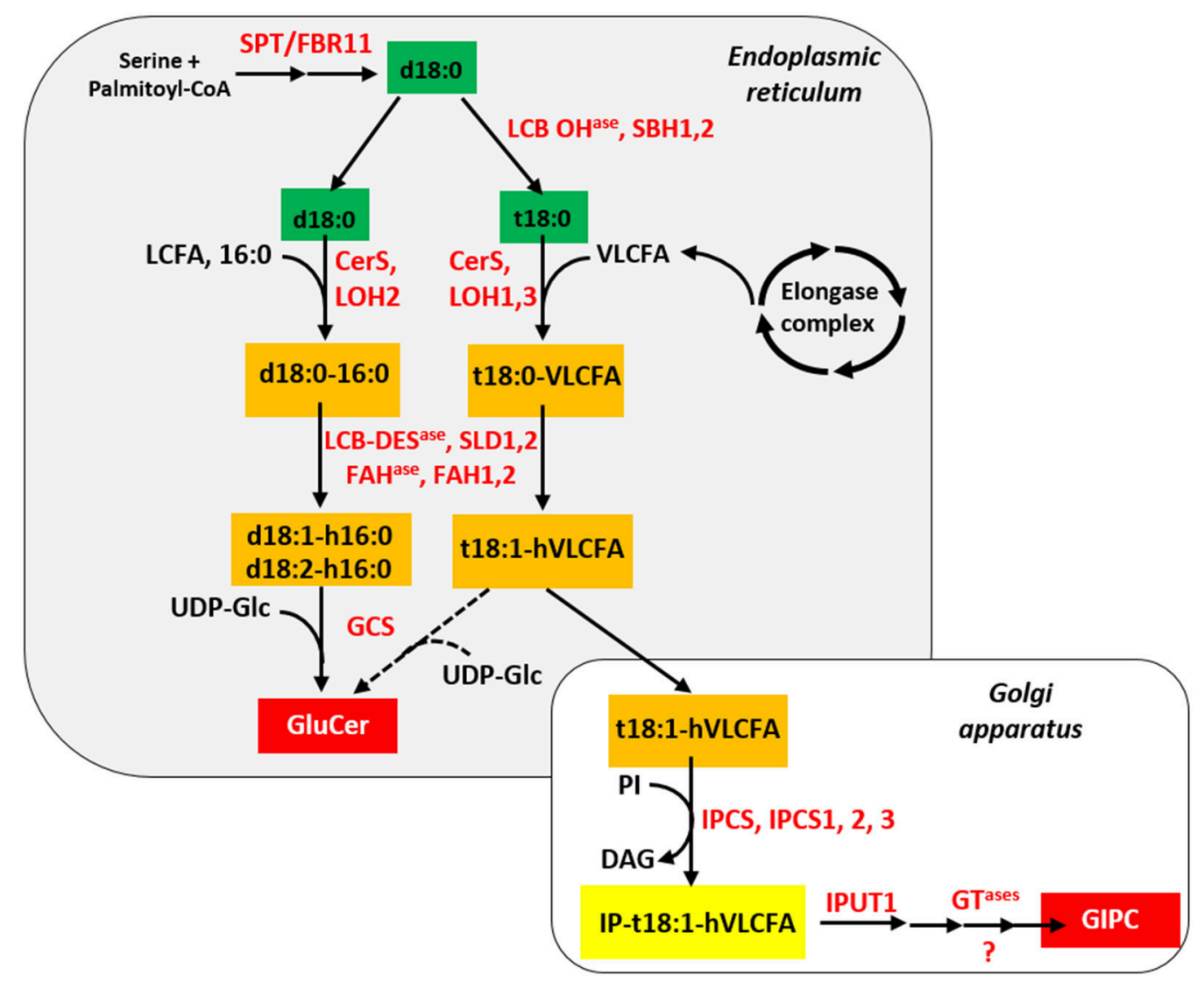

FIGURE 2 | Plant sphingolipid synthesis. (A) The four classes of plant sphingolipids (from Cacas et al., 2012a). The left panel displays the nine molecular species of long-chain bases found in plants, from top to bottom: sphinganine/dihydrosphingosine, d18:0; sphingosine/sphing-4(trans)-enine, d18:1 $\Delta 4(E)$;

sphing-8(trans)-enine, d18:1 $\Delta 8(E)$; sphing-8(Cis)-enine, d18:1 $\Delta 8(Z)$; sphinga-4,8(trans, trans)-dienine, d18:1 ${ }^{\Delta 4,8(E, E)}$; sphinga-4,8(trans, cis)-dienine, d18:1 $\Delta 4,8(E, Z)$; 


\section{FIGURE 2 | Continued}

phytosphingosine/4-hydroxysphinganine, t18:0; 4-hydroxysphing-8(trans)-enine, t18:1 $\Delta 8(E)$; 4-hydroxysphing-8(cis)-enine, t18:1 $\Delta 8(Z)$. On the right panel (from top to bottom) are showed a ceramide (sphing-4(trans)-enine- $N$-octadecanoic acid), a glucosylceramide (Glucosyl-O- $\beta$-ceramide

(sphing-4(trans)-enine-N-octadec-9(cis)-enoic acid)) and a glycosyl-inositolphosphoryl-ceramide (N-acetylglucosamine-glucuronic acid-inositolphosphoryl-ceramide (4-hydroxysphing-8(cis)-enine-N-tetracosanoic acid)). (B) In situ simplified view of the plant sphingolipid biosynthesis pathway. Except for the serine and palmitoyl-CoA precursors, sphingolipid metabolites appear in colored rectangles: green for long-chain bases, orange for ceramides and red for final products like glucosylceramides (GluCer) and glycosyl-inositolphosphoryl-ceramides (GIPC). Nomenclature for ceramide is as follows: for instance, d18:0-16:0 indicates that the long-chain base corresponds to sphinganine and the fatty acid is a palmitoyl moiety, respectively. Enzymes are written in red. Abbreviations: CerS, ceramide synthase; DAG, diacylglycerol; FAH ${ }^{\text {ase }}$, fatty acid hydroxylase; GCS, glucosylceramide synthase; GT ${ }^{\text {ase }}$, glycosyl-transferase; IPCS, inositolphosphoryl-ceramide synthase; IPUT1, INOSITOLPHOSPHORYL-CERAMIDE GLUCURONOSYL-TRANSFERASE 1; LCB, long-chain base; LCB DES ${ }^{\text {ase, }}$, LCB desaturase; LCB OH ase, LCB hydroxylase; LCFA, long-chain fatty acid; LOH, LAG ONE HOMOLOG; PI, phosphatidylinositol; SPT/FBR11, serine palmitoyl-CoA transferase/FUMONISIN-RESITANT 11; SLD1,2, SPHINGOLIPID LCB $\triangle 8$ DESAUTRASE 1,2; UDP-Glc, uridine diphosphate-glucose; VLCFA, very-long-chain fatty acid.

et al., 2010; Cacas et al., 2016c), that sphingolipids contain most VLCFA produced in leaves.

\section{Scenario 1: Interplay between Very-Long-Chain Fatty Acids and the Ceramide and LCB Signals}

Schematically, GIPC represent two third of total sphingolipids within photosynthetic plant cells whereas Glucer accounts for the other third (Markham et al., 2006). This is coherent with their role as structural membrane elements. By contrast, free Cer and LCB, as intermediate metabolites, are weakly present in leaf organs (Markham et al., 2006). Defining genuine molecular signals as locally- and timely-produced molecules that act at infinitesimal concentrations, it might not be surprising that the signaling function of both LCB and ceramides under stressful conditions could be conserved across kingdoms. Even though exact molecular substratum for sphingolipid control of cell fate is far from being deciphered, it is assumed that, in plants, like in animals, accumulation of free Cer or LCB would kill cells whereas that of their phosphorylated counterparts would have survival-promoting effects in response to stress. In plants, when chemically-perturbed or genetically-disrupted, most steps of the sphingolipid biosynthesis pathway can lead to conditional cell death phenotypes or spontaneous pathogen resistancemimicking hypersensitive-like foliar lesions. These observations can be tentatively explained by a disequilibrium of the tightlyregulated intracellular balance between unfettered LCB and LCBphosphate (LCB-P). Compelling evidence for this notion was provided by exogenous LCB application, the use of the mycotoxin fumonisin B1 that inhibits CerS and mutation (fumonisinresistant 11, fbr11) in a subunit of the LCB-forming enzyme SPT (Alden et al., 2011; Berkey et al., 2012). Another crucial regulatory node may also rely on the Cer/Cer-phosphate (Cer$\mathrm{P})$ ratio, as substantiated by genetic data regarding the ceramide kinase ACCELERATED CELL DEATH 5 (Liang et al., 2003), the Cer-P transferase ACCELERATED CELL DEATH 11 (Simanshu et al., 2014) and inositolphosphoryl-ceramide synthase (IPCS) (Wang et al., 2008).

Recent work addressing Arabidopsis CerS specificity toward FA chain length in vitro established that $\mathrm{LOH} 1 / 3$ preferentially use VLCFA as substrates whereas LOH2 rather forms sixteen carbon-long fatty acid (16:0)-containing Cer (Luttgeharm et al., 2016). While LOH1/3 overexpressing lines showed only little changes in their sphingolipid profiles, a strong enrichment in Cer molecular species with 16:0 FA was recorded for those that overexpressed LOH2. Additional phenotypical traits of the latter overexpressor plants were reminiscent of lesion-mimic mutants that exhibit enhanced disease resistance and develop hypersensitive cell death symptoms under restrictive environment, despite the absence of pathogens. These traits included increased salicylic acid concentrations and PATHOGENESIS-RELATED 1 (PR1) gene expression, localized programmed cell death and severe dwarfism (Luttgeharm et al., 2015). Consistently, loh1 null mutants displayed discrete spontaneous foliar lesions correlated with strong constitutive PR1 expression and significant elevation in 16:0-containing Cer and GluCer contents (Ternes et al., 2011). Although FA-mediated structural effects cannot totally be ruled out for explaining the aforementioned phenotypes (see below), these data may also pinpoint the importance of the aliphatic chain length present in Cer destined to signaling purposes, suggesting the occurrence of a supplementary regulatory level to that driven by the solely balance of phosphorylated/non-phosphorylated metabolites. In line with this postulate, it is thus tempting to speculate that stress-induced rise in VLCFA concentrations might alter intracellular Cer pool composition and, subsequently, impact related signaling routes. Moving further this way, it is also plausible that, following stress exposure, quantitative and/or qualitative modifications of VLCFA pool indirectly influence LCB synthesis due to metabolic reorientation, as suggested by the analysis of LCB hydroxylase mutants (Chen et al., 2008). The existence for two Arabidopsis sphingosine kinases with sharply different substrate specificity also reinforces the idea that both VLCFA and LCB chains could matter when it comes to signaling stress (Guo et al., 2011). Since the Arabidopsis MITOGENACTIVATED PROTEIN KINASE 6 (MPK6) has been recently described as a downstream effector of sphingolipid-induced cell death (Saucedo-García et al., 2011), it could represent a privileged target for investigating the interplay between VLCFA and LCB/Cer-contingent signaling under stressful conditions.

\section{Scenario 2: The Membrane Trafficking Link}

The plant endomembrane system (ES) is a complex, dynamic and intricate membrane-composed web that encompasses the ER, Golgi apparatus (GA), trans-Golgi network (TGN), the endocytic, vacuolar, and autophagic compartments, the plasma membrane (PM) and all vesicles that shuttle in between these organelles. It provides infrastructure for the secretory pathway which is dedicated to both protein and lipid sorting (Cacas, 2010). Apart from its crucial role in maintaining cellular homeostasis, 
the ES has also recently emerged as an essential component of plant tolerance to stress (for review, see Cacas, 2015) and, this may be linked to VLCFA-containing sphingolipids, like GluCer and GIPC.

Early indirect insights into a potential relationships between GluCer and protein trafficking came from clinical studies focused on molecular mechanisms underpinning Gaucher disease. A bench of mutations that totally or partially invalidate the two glucocerebrosidases-encoding genes-involved in lysosomal degradation of GluCer-was found to cause ER to dysfunction, leading to enzyme sorting impairment ( $\mathrm{Yu}$ et al., 2007). In plants, regulation of GluCer homeostasis is as essential as in animal models. In Arabidopsis, only one gene codes for the ER-localized glucosylceramide synthase, or GCS. Null gcs mutants fail to develop beyond seedling stage and are defective for organogenesis. In addition, $g c s(-/-)$ cells display altered GA morphology indicative of a probable perturbed cell secretion activity (Msanne et al., 2015). Accordingly, groundbreaking work carried out by the team of Dr. Moreau (CNRS, Bordeaux, France) pointed out that chemical blunting of GCS activity resulted in (i) GA disaggregation into vesicles, (ii) reduced externalization of an apoplastic fluorescent protein ectopically expressed (N-SecYFP), and (iii) both mislocalization and secretion diminishment of the PM-located $\mathrm{H}^{+}$-ATPase PMA4 (Melser et al., 2010). Transient overexpression of the two latter proteins (N-SecYFP and PMA4) in a WT genetic background was further reported to augment sterol and GluCer contents whereas that of soluble proteins and membrane proteins which do not traffic beyond GA was unable to do so (Melser et al., 2010). Combined, these findings put forward the case for GluCer, along with sterols, as potent protein sorting mediators in the late secretory pathway. Two main explanations can be envisaged in this context. On the one hand, one can assume that GluCer and sterols exerts their function through a chaperone-like activity, stabilizing native structure of specific integral membrane cargo proteins that they escort from GA to PM. On the other hand, it has been proposed that glycosphingolipids could impose positive curvature to membranes, thereby facilitating vesicle fusion (Barth et al., 2010; Molino et al., 2014). In this regard, the few data that are currently available in the literature do not allow discriminating among these two hypotheses yet.

Joined study between our team (Faure's lab, INRA, Versailles, France) and that of Markham (Danforth Plant Science Center, Saint Louis, Missouri, USA) documented the impact of loh mutations on Arabidopsis root architectural modifications in relation with sphingolipid profile and secretion of PM-resident proteins (Markham et al., 2011). As corroborated latter on by Luttgeharm et al. (2016), it was demonstrated that double loh1/loh3 mutants overaccumulated 16:0-containing complex glycosphingolipids at the expense of VLCFA-containing ones, reflecting the substrate specificity of the remaining CerS activity borne by LOH2. Remarkably, this marked trend was correlated with PM-targeting default for two auxin carrier proteins; the latter of which being characterized by a loss of cell polarity, a strong inhibition of hormonal transport and the absence of lateral root initiation at macroscopic level. Again, experimental data argued in favor of a post-Golgi trafficking defect when sphingolipid synthesis was manipulated (Markham et al., 2011). Together with those of Melser's work, our results provide unequivocal evidence for the requirement of VLCFA-containing sphingolipids for protein transport, even though the respective contribution of GluCer and GIPC in this process could not have been ascertained. Back to signaling topic, it is possible that VLCFA anabolism adjustment participate in accommodating cell secretory activity to challenging environmental conditions. In fact, several published examples already indicate that effective intracellular membrane trafficking is necessary for transducing specific protein-based signals during plant immunity (for reviews, see Berkey et al., 2012; Teh and Hofius, 2014). Among them can be cited the immune receptor EIX2 (ETHYLENEINDUCING XYLANASE 2) from tomato plants, the endosomal internalization of which is necessary for mounting proper defense response (Sharfman et al., 2011). Another striking example is that of the relocalization of the RPW8 resistance protein to extrahaustorial membranes at the host-pathogen interface in response to specific fungi and oomycetes (Wang et al., 2009). Moreover, numerous protein regulators that control cell death outcome in response to abiotic and biotic stress are distributed along the ES (Cacas, 2015). This sustains the idea that VLCFA could define a late secretory pathway dedicated to some stress signaling components. One of the main challenges in next future will be to understand the role of one such path under abiotic constraints. Distinguishing how VLCFA could, respectively, influence antimicrobial protein burden to be excreted and transport of specific regulatory proteins following pathogen infection will probably represent a difficult task too.

\section{Scenario 3: The Membrane Microdomain Hypothesis}

Membrane microdomains can be defined as islands composed of lipids and proteins that laterally segregate from the rest of the PM. They are highly enriched in sterols, sphingolipids and signaling proteins (Boutté and Grebe, 2009). Their size was described to fit nanometer to micrometer scales. Originally named raft, microdomains were identified in mammalian systems where they notably act as platforms responsible for the launching of apoptotic and inflammation signaling cascades (Malorni et al., 2007; George and Wu, 2012). First experimental evidence for their occurrence in plants was provided by biochemical approaches based on the purification of detergentinsoluble membranes (DIM) through floatation on step sucrose gradient (Mongrand et al., 2004). Since then, accumulation of pharmacological, proteomic, microscopy, and genetic data ended the controversy on plant microdomain existence. Thus, it is now broadly accepted that DIM do not represent functional equivalents of microdomains, but rather constitutes one way of assessing their chemical composition (Cacas et al., 2012a).

Previously, a strong enrichment in tri-hydroxylated LCB in PM fractions purified from two plant species was reported (Borner et al., 2005; Lefebvre et al., 2007). Given that this class of LCB is mainly encountered in GIPC (for review, see Pata et al., 2010), this led the plant lipid community to the reasonable hypothesis that GIPC reside, for the most part, 
in PM. Having established methods for purifying GIPC and characterizing their composition (Buré et al., 2011; Cacas et al., $2012 b$ ), we tested for this assumption using tobacco plants and cell cultures. Not astonishingly, we found that (i) tobacco GIPC contain the large majority of the intracellular VLCFA pool, and (ii) VLCFA moieties engaged in these lipids were predominantly hydroxylated on carbon position 2 (noted hVLCFA). Exploiting this unique opportunity for probing GIPC repartition within the ES uncovered a marked hVLCFA gradient along the secretory pathway that reaches an optimum in DIM

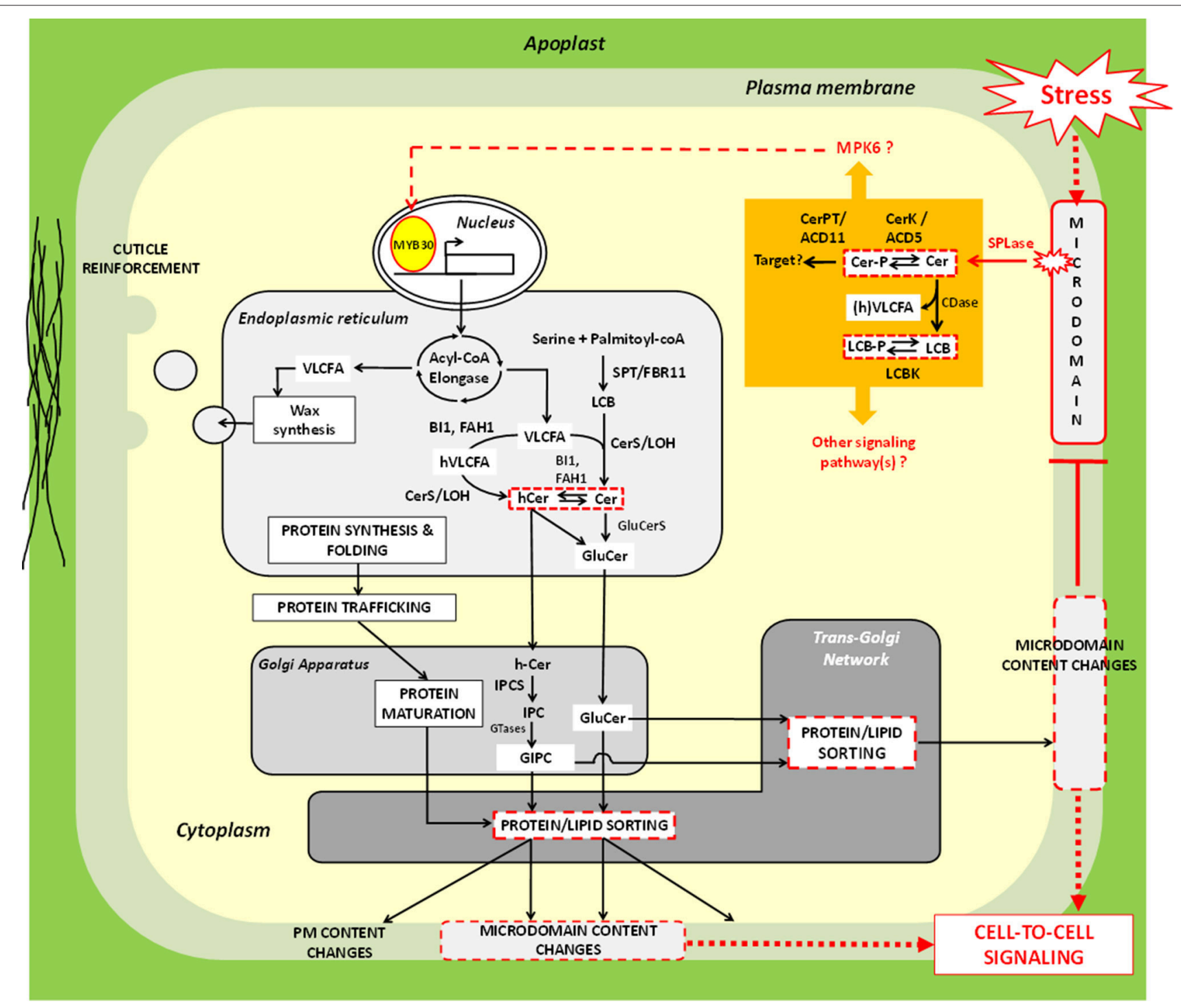

FIGURE 3 | Molecular model explaining how very-long-chain fatty acids could participate in stress signaling response in plant cells. In mammalian systems, extrinsic cues can be perceived at the plasma membrane by means of microdomains. A comparable hypothesis can be emitted for plant models. It is possible that "sphingolipase D" (SPLase) like the one identified by Tanaka et al. (2013) is recruited to microdomains following stress exposure, and releases ceramide (Cer) molecules from complex glycosphingolipids in situ. Free Cer could either directly act as signals or be processed into Cer-P by the kinase ACCELERATED CELL DEATH 5 (ACD5). The ceramide-1-phosphate tranferase ACCELERATED CELL DEATH 11 (ACD11) may participate to this signaling cascade as well, though its exact mode of action remains to be clarified. In addition, Cer could also be hydrolyzed by ceramidase (CDase) into LCB that can, in turn, be phosphorylated; one such activity have indeed been documented in plants (Pata et al., 2010). Although little is still known about molecular actors that relay LCB/Cer signals (orange part of the figure), the work of Saucedo-García et al. (2011) identified MITOGEN-ACTIVATED PROTEIN KINASE 6 (MPK6) as a good candidate for exerting this function. The transcription factor MYB30 represents a potential downstream target of sphingolipid-induced phosphorylation events, since it was found to up-regulate acyl-CoA elongase genes in response to environmental cues. Resulting very-long-chain fatty acid (VLCFA) production could then be utilized for strengthening cuticle, especially epicuticular wax. Alternatively, VLCFA could be incorporated into sphingolipids. Modifications of sphingolipid composition and/or level can impact protein sorting at the TGN and, therefore, probably modulate targeting of specific stress responsive signaling proteins to PM. From this postulate, it seems coherent to envisage that modifications of the secreted lipids and proteins influence PM lateral segregation. Expected consequences of this segregation phenomenon could be changes in microdomain content that could feature extracellular signaling process(es) and/or negative feedback regulation. Of note, elements in the picture that represent regulatory nodes involving VLCFA (Hypotheses 1-3) are delineated by red continue or discontinued lines. Red discontinued arrows indicate steps which has not been experimentally demonstrated. For additional abbreviations, refer to the legend of Figure 2. 
fractions. Further investigations brought to light that GIPC amount to approximately 60 mole \% of total DIM lipids; the polyglycosylated forms being only present in the external hemilayer and clustering in $35 \mathrm{~nm}$-sized microdomains. Combined biophysical and modeling strategies also showed that hVLCFA could strongly interact with sterols and interdigitate between the two membrane leaflets, which likely explains the synergistic effect of GIPC and sterol in structuring membrane in vitro (Cacas et al., 2016c). Hence, in addition to their postulated role in protein sorting at the TGN, glycosphingolipids may also be involved in stress response with respect to their lateral segregation within PM.

Nagano et al. $(2009,2012)$ shed light on possible links between hVLCFA and stress acclimation. Working on the conserved family of ER-resident cell death regulators, known as BAX INHIBITORS (BI), the authors showed that At-BI1 interacts with the electron donor, cytochrome b5, the latter of which can in turn associate with FATTY ACID HYDROXYLASE1 (FAH1) catalyzing the hydroxylation of VLCFA. Overexpression of At-BI1 was also correlated with higher hVLCFA contents and decreased cell death under stressful conditions. Conversely, knock-down FAH1 plants displayed decreased hVLCFA amounts and enhanced sensitivity to hydrogen peroxide, suggesting that At-BI1 protects cells by activating FAH1. Now, given that hCer exhibit pro-survival properties in animal cells (Young et al., 2013), one can hypothesize that the hCer/Cer balance under the control of BI1/FAH1 dictates the progression rate of hypersensitive foliar lesions in response to pathogen attack. This attractive theory cannot, however, justify by itself MYB30-driven transcriptional induction of the elongase complex genes (Raffaele et al., 2008) and the resulting massive increase in VLCFA concentrations reported in this context. Alternatively, one can envisage that modulating hVLCFA synthesis could affect GIPC composition and/or concentration and, consequently, impact raft signaling events. In vivo and in vitro experiments have proven that lateral segregation of membrane proteins is dependent on that of lipids, and vice versa (for review, see Volmer and Ron, 2015). In animal systems, recruitment or disassembly of signaling actors can be achieved through respective coalescence or dissociation of microdomains, thereby provoking initiation or termination of signaling cascades at the PM (Malorni et al., 2007; George and Wu, 2012). A comparable situation has already been proposed to take place in BI1-overexpressing transgenics (Ishikawa et al., 2015) and during plant innate immunity (Keinath et al., 2010). In addition, both biotic and abiotic stresses are known to provoke changes in protein content of microdomains (Minami et al., 2009; Stanislas et al., 2009).

Findings that elongase complex-encoding genes are under transcriptional control upon environmental cues (Joubès et al., 2008; Raffaele et al., 2008; Xie et al., 2015) implies that modulation of hVLCFA steady-state levels is implicated in a secondary signaling wave, possibly regulating microdomaincoordinated events. Indeed, for transcriptional reprogramming to occur, stress perception must be completed and signal transduction engaged. This is quite distinct from, but not incompatible with the regular picture documented in the mammalian literature where external constraints are generally described to promote rapid relocalization of sphingolipidmodifying enzymes to microdomains, freeing Cer or LCB moieties and, per se, generating primary signals relayed by downstream effectors. Actually, one can expect that both situations could cohabit in the same challenged plant cell with different timing. In this case, raft sphingolipids could feature a reservoir of signals to be mobilized early following stress application, as sustained by the recent discovery of sphingolipase D activities in plants (Tanaka et al., 2013). Once initiated, such signaling cascades would contribute to activate hVLCFA neo-synthesis, ultimately fine-tuning microdomain composition. The latter phenomena could either benefit to intercellular communication or simply operate as a negative feedback that abrogate the production of signaling molecules by microdomains. Testing for this seductive concept will require a careful in situ dosage of hVLCFA-containing sphingolipids over time. With the recent advances in mass spectrometry-based chemical imaging, this deadlock should be broken in a close future.

\section{TENTATIVE MODEL-PUZZLING OUT VERY-LONG-CHAIN FATTY ACID-CONTINGENT SIGNALING PATHWAYS}

Although the involvement of VLCFA in stress response is not contestable, interpretation of this experimental fact may remain delicate in light of the currently available data. Pleiotropic consequences of VLCFA level alterations also render this task complicated. Based on the observation that VLCFA are highly enriched in sphingolipids, we have, however, suggested, and explored three non-exclusive, molecular scenarii to tentatively explain how insoluble molecules -like VLCFA - could participate in stress signaling response. These hypotheses, which are experimentally testable, are summarized in a model presented in the Figure 3. By analogy with animals systems, it is envisaged that stress perception could trigger recruitment of yet-to-be cloned "sphingolipases" to microdomains. Enzymatically-released Cer(-P) skeletons could then either directly serve as signals or be further processed, activating a potent downstream effector, the kinase MPK6. One possible target of this phosphorylation cascade could be the transcription factor MYB30, which is known to upregulate expression of the elongase complex-encoded genes upon pathogen attack and hypoxia. As also supported by several studies, changes in the composition and/or level of VLCFAcontaining lipids impact protein sorting at the TGN. This could represent a potential regulatory mechanism whereby targeting of specific signaling proteins to PM could be spatiotemporally modulated depending on stressed cell requirements. Adding a supplemental layer of regulation, these changes in sphingolipids certainly alter microdomain content, and consequently, should also influence PM-coordinated signaling events. Beyond the response plasticity conferred to plant cells by a dual lipid/protein-based rheostat, this model raises the interesting question as to how this molecular scheme 
contributes to stress acclimation. Is this linked to intercellular communication, negative feedback control of microdomaindependent signaling or both?

\section{AUTHOR CONTRIBUTIONS}

AD provided Table 2, JC defined hypotheses, wrote the manuscript, and drew figures.

\section{REFERENCES}

Adarme-Vega, T. C., Thomas-Hall, S. R., Lim, D. K., and Schenk, P. M. (2014). Effects of long chain fatty acid synthesis and associated gene expression in microalga Tetraselmis sp. Mar. Drugs. 12, 3381-3398. doi: 10.3390/md12063381

Alden, K. P., Dhondt-Cordelier, S., McDonald, K. L., Reape, T. J., Ng, C. K., McCabe, P. F., et al. (2011). Sphingolipid long chain base phosphates can regulate apoptotic-like programmed cell death in plants. Biochem. Biophys. Res. Commun. 410, 574-580. doi: 10.1016/j.bbrc.2011.06.028

Arisz, S. A., Testerink, C., and Munnik, T. (2009). Plant PA signaling via diacylglycerol kinase. Biochim. Biophys. Acta. 1791, 869-875. doi: 10.1016/j.bbalip.2009.04.006

Bach, L., and Faure, J. D. (2010). Role of very-long-chain fatty acids in plant development, when chain length does matter. C. R. Biol. 333, 361-370. doi: 10.1016/j.crvi.2010.01.014

Barth, B. M., Gustafson, S. J., Young, M. M., Fox, T. E., Shanmugavelandy, S. S., Kaiser, J. M., et al. (2010). Inhibition of NADPH oxidase by glucosylceramide confers chemoresistance. Cancer Biol. Ther. 10, 1126-1136. doi: $10.4161 /$ cbt.10.11.13438

Berkey, R., Bendigeri, D., and Xiao, S. (2012). Sphingolipids and plant defense/disease: the "death" connection and beyond. Front. Plant Sci. 3:68. doi: 10.3389/fpls.2012.00068

Borner, G. H. H., Sherrier, J. D., Weimar, T., Michaelson, L. V., Hawkins, N. D., MacAskill, A., et al. (2005). analysis of detergent-resistant membranes in Arabidopsis. Evidence for plasma membrane lipid rafts. Plant Physiol. 137, 104-116. doi: 10.1104/pp.104.053041

Boutté, Y., and Grebe, M. (2009). Cellular processes relying on sterol function in plants. Curr. Opin. Plant Biol. 12, 705-713. doi: 10.1016/j.pbi.2009.09.013

Buré, C., Cacas, J. L., Wang, F., Domergue, F., Mongrand, S., and Schmitter, J. M. (2011). Fast screening of highly glycosylated plant sphingolipids by tandem mass spectrometry. Rapid Commun. Mass Spectrom. 25, 3131-3145. doi: $10.1002 / \mathrm{rcm} .5206$

Cacas, J. L. (2010). Devil inside: does plant programmed cell death involve the endomembrane system? Plant Cell Env. 33, 1453-1473. doi: 10.1111/j.13653040.2010.02117.x

Cacas, J. L. (2015). "Out for a walk along the secretory pathway during programmed cell death," in Plant Programmed Cell Death, eds A. H. Gunawardena and P. F. McCabe (Powell, WY: Springer), 123-161.

Cacas, J. L., Buré, C., Grosjean, K., Gerbeau-Pissot, P., Lherminier, J., Rombouts, Y., et al. (2016c). Revisiting plant plasma membrane lipids in tobacco: a focus on sphingolipids. Plant Physiol. 170, 367-384. doi: 10.1104/pp.15.00564

Cacas, J. L., Furt, F., Le Guédart, M., Bayer, E., Schmitter, J. M., Buré, C., et al. (2012a). Lipids of plant membrane rafts. Prog. Lipid Res. 51, 272-299. doi: 10.1016/j.plipres.2012.04.001

Cacas, J. L., Gerbeau-Pissot, P., Fromentin, J., Cantrel, C., Thomas, D., Jeannette, E., et al. (2016a). Diacylglycerol kinases activate tobacco NADPH oxidasedependent oxidative burst in response to cryptogein. Plant Cell Environ. doi: 10.1111/pce.12771. [Epub ahead of print].

Cacas, J. L., Melser, S., Domergue, F., Joubès, J., Bourdenx, B., Schmitter, J. M., et al. (2012b). Rapid nanoscale quantitative analysis of plant sphingolipid long chain bases by GC-MS. Anal. Bioanal. Chem. 403, 2745-2755. doi: 10.1007/s00216012-6060-1

Cacas, J. L., Pré, M., Pizot, M., Cissoko, M., Diedhiou, I., Jalloul, A., et al. (2016b). GhERF-IIb3 regulates accumulation of jasmonate and leads to enhanced cotton

\section{ACKNOWLEDGMENTS}

We would like to warmly thank Dr. Palauqui JC (INRA, Versailles) for critical reading and enthusiastic discussions. We also would like to thank the editors for inviting us contributing to this special issue. We declare no conflict of interest with any works cited in this article. We apologize in advance for not citing colleagues' research due to space limitation.

resistance to blight disease. Mol. Plant Pathol. doi: 10.1111/mpp.12445. [Epub ahead of print].

Cacas, J. L., Vailleau, F., Davoine, C., Ennar, N., Agnel, J. P., Tronchet, M., et al. (2005). The combined action of 9 lipoxygenase and galactolipase is sufficient to bring about programmed cell death during tobacco hypersensitive response. Plant Cell Env. 28, 1367-1378. doi: 10.1111/j.1365-3040.2005.01369.x

Chen, M., Markham, J. E., Dietrich, C. R., Jaworski, J. G., and Cahoon, E. B. (2008). Sphingolipid long-chain base hydroxylation is important for growth and regulation of sphingolipid content and composition in Arabidopsis. Plant Cell 20, 1862-1878. doi: 10.1105/tpc.107.057851

Fehling, E., and Mukherjee, K. D. (1991). Acyl-CoA elongase from a higher plant (Lunaria annua): metabolic intermediates of very-long chain acyl-CoA products and substrate specificity. Biochim. Biophys. Acta 1082, 239-246. doi: 10.1016/0005-2760(91)90198-q

Garcion, C., Lamotte, O., Cacas, J. L., and Métraux, J. P. (2014). “Mechanisms of defence to pathogens: biochemistry and physiology," in Induced Resistance For Plant Defence: A Sustainable Approach For Crop Protection, eds D. Walters, A. Newton, and G. Lyon (West Sussex: Wiley-Blackwell), 106-136.

George, K. S., and Wu, S. (2012). Lipid raft: a floating island of death or survival. Toxicol. Appl. Pharmacol. 259, 311-319. doi: 10.1016/j.taap.2012.01.007

Glauser, G., and Wolfender, J. L. (2013). A non-targeted approach for extended liquid chromatography-mass spectrometry profiling of free and esterified jasmonates after wounding. Methods Mol. Biol. 1011, 123-134. doi: 10.1007/978-1-62703-414-2_10

Gronnier, J., Germain, V., Gouguet, P., Cacas, J. L., and Mongrand, S. (2016). GIPC: Glycosyl Inositol Phospho Ceramides, the major sphingolipids on earth. Plant Signal. Behav. 11:e1152438. doi: 10.1080/15592324.2016.1152438

Guo, L., Mishra, G., Taylor, K., and Wang, X. (2011). Phosphatidic acid binds and stimulates Arabidopsis sphingosine kinases. J. Biol. Chem. 286, 13336-13345. doi: 10.1074/jbc.M110.190892

Han, P. P., Zhou, J., and Yuan, Y. J. (2009). Analysis of phospholipids, sterols, and fatty acids in Taxus chinensis var. mairei cells in response to shear stress. Biotechnol. Appl. Biochem. 54, 105-112. doi: 10.1042/BA20090102

Haslam, T. M., and Kunst, L. (2013). Extending the story of very-long-chain fatty acid elongation. Plant Sci. 210, 93-107. doi: 10.1016/j.plantsci.2013.05.008

Ichimura, A., Hasegawa, S., Kasubuchi, M., and Kimura, I. (2014). Free fatty acid receptors as therapeutic targets for the treatment of diabetes. Front. Pharmacol. 5:236. doi: 10.3389/fphar.2014.00236

Ishikawa, T., Aki, T., Yanagisawa, S., Uchimiya, H., and Kawai-Yamada, M. (2015). Overexpression of BAX INHIBITOR-1 links plasma membrane microdomain proteins to stress. Plant Physiol. 169, 1333-1343. doi: 10.1104/pp.15. 00445

Jia, Y., and Li, W. (2015). Characterisation of lipid changes in ethylenepromoted senescence and its retardation by suppression of phospholipase D $\delta$ in Arabidopsis leaves. Front. Plant Sci. 6:1045. doi: 10.3389/fpls.2015.01045

Joubès, J., Raffaele, S., Bourdenx, B., Garcia, C., Laroche-Traineau, J., Moreau, P., et al. (2008). The VLCFA elongase gene family in Arabidopsis thaliana: phylogenetic analysis, 3D modelling and expression profiling. Plant Mol. Biol. 67, 547-566. doi: 10.1007/s11103-008-9339-z

Keinath, N. F., Kierszniowska, S., Lorek, J., Bourdais, G., Kessler, S. A., ShimosatoAsano, H., et al. (2010). PAMP (pathogen-associated molecular pattern)induced changes in plasma membrane compartmentalization reveal novel components of plant immunity. J. Biol. Chem. 285, 39140-39149. doi: 10.1074/jbc.M110.160531 
Kobayashi, K., Masuda, T., Takamiya, K., and Ohta, H. (2006). lipid alteration during phosphate starvation is regulated by phosphate signaling and auxin/cytokinin cross-talk. Plant J. 47, 238-248. doi: 10.1111/j.1365313X.2006.02778.x

Lefebvre, B., Furt, F., Hartmann, M. A., Michaelson, L. V., Carde, J. P., Sargueil-Boiron, F., et al. (2007). Characterization of Lipid Rafts from Medicago truncatula root plasma membranes: a proteomic study reveals the presence of a raft-associated redox system. Plant Physiol. 144, 402-418. doi: 10.1104/pp.106.094102

Li, H. Y., and Chye, M. L. (2004). Arabidopsis acyl-CoA-binding protein ACBP2 interacts with an ethylene-responsive element-binding protein, AtEBP, via its ankyrin repeats. Plant Mol. Biol. 54, 233-243. doi: 10.1023/B:PLAN.0000028790.75090.ab

Li, H. Y., Xiao, S., and Chye, M. L. (2008). Ethylene- and pathogen-inducible Arabidopsis acyl-CoA-binding protein 4 interacts with an ethylene-responsive element binding protein. J. Exp. Bot. 59, 3997-4006. doi: 10.1093/jxb/ern241

Liang, H., Yao, N., Song, J. T., Luo, S., Lu, H., and Greenberg, J. T. (2003). Ceramides modulate programmed cell death in plants. Genes Dev. 17, 2636-2641. doi: 10.1101/gad.1140503

Li-Beisson, Y., Shorrosh, B., Beisson, F., Andersson, M. X., Arondel, V., Bates, P. D., et al. (2010). Acyl-Lipid Metabolism. Arabidopsis Book 8:e0133. doi: 10.1199/tab.0133

Los, D. A., and Murata, N. (2004). Membrane fluidity and its roles in the perception of environmental signals. Biochim. Biophys. Acta 1666, 142-157. doi: 10.1016/j.bbamem.2004.08.002

Luttgeharm, K. D., Cahoon, E. B., and Markham, J. E. (2016). Substrate specificity, kinetic properties and inhibition by fumonisin B1 of ceramide synthase isoforms from Arabidopsis. Biochem. J. 473, 593-603. doi: 10.1042/BJ20150824

Luttgeharm, K. D., Chen, M., Mehra, A., Cahoon, R. E., Markham, J. E., and Cahoon, E. B. (2015). Overexpression of Arabidopsis ceramide synthases differentially affects growth, sphingolipid metabolism, programmed cell death, and mycotoxin resistance. Plant Physiol. 169, 1108-1117. doi: 10.1104/pp.15.00987

Malorni, W., Giammarioli, A. M., Garofalo, T., and Sorice, M. (2007). Dynamics of lipid raft components during lymphocyte apoptosis: the paradigmatic role of GD3. Apoptosis 12, 941-949. doi: 10.1007/s10495-007-0757-1

Marichali, A., Dallali, S., Ouerghemmi, S., Sebei, H., Casabianca, H., and Hosni, K. (2016). Responses of Nigella sativa L. to Zinc excess: focus on germination, growth, yield and yield components, lipid and terpene metabolism, and total phenolics and antioxidant activities. J. Agric. Food Chem. 64, 1664-1675. doi: 10.1021/acs.jafc.6b00274

Markham, J. E., Li, J., Cahoon, E. B., and Jaworski, J. G. (2006). Separation and identification of major plant sphingolipid classes from leaves. J. Biol. Chem. 281, 22684-22694. doi: 10.1074/jbc.M604050200

Markham, J. E., Lynch, D. V., Napier, J. A., Dunn, T. M., and Cahoon, E. B. (2013). Plant sphingolipids: function follows form. Curr. Opin. Plant Biol. 16, 350-357. doi: 10.1016/j.pbi.2013.02.009

Markham, J. E., Molino, D., Gissot, L., Bellec, Y., Hématy, K., Marion, J., et al. (2011). Sphingolipids containing very-long-chain fatty acids define a secretory pathway for specific polar plasma membrane protein targeting in Arabidopsis. Plant Cell. 23, 2362-2378. doi: 10.1105/tpc.110.080473

Melser, S., Batailler, B., Peypelut, M., Poujol, C., Bellec, Y., Wattelet-Boyer, V., et al. (2010). Glucosylceramide biosynthesis is involved in Golgi morphology and protein secretion in plant cells. Traffic 11, 479-490. doi: 10.1111/j.16000854.2009.01030.x

Millar, A. A., and Kunst, L. (1997). Very-long-chain fatty acid biosynthesis is controlled through the expression and specificity of the condensing enzyme. Plant J. 12, 121-131. doi: 10.1046/j.1365-313X.1997.12010121.x

Minami, A., Fujiwara, M., Furuto, A., Fukao, Y., Yamashita, T., Kamo, M., et al. (2009). Alterations in detergent-resistant plasma membrane microdomains in Arabidopsis thaliana during cold acclimation. Plant Cell Physiol. 50, 341-359. doi: $10.1093 /$ pcp/pcn202

Molino, D., Van der Giessen, E., Gissot, L., Hématy, K., Marion, J., Barthelemy, J., et al. (2014). Inhibition of very long acyl chain sphingolipid synthesis modifies membrane dynamics during plant cytokinesis. Biochim. Biophys. Acta 1842, 1422-1130. doi: 10.1016/j.bbalip.2014.06.014

Mongrand, S., Morel, J., Laroche, J., Claverol, S., Carde, J. P., Hartmann, M. A., et al. (2004). Lipid rafts in higher plant cells: purification and characterization of Triton X-100-insoluble microdomains from tobacco plasma membrane. J. Biol. Chem. 279, 36277-36286. doi: 10.1074/jbc.m403440200

Msanne, J., Chen, M., Luttgeharm, K. D., Bradley, A. M., Mays, E. S., Paper, J. M., et al. (2015). Glucosylceramides are critical for cell-type differentiation and organogenesis, but not for cell viability in Arabidopsis. Plant J. 84, 188-201. doi: $10.1111 /$ tpj. 13000

Nagano, M., Ihara-Ohori, Y., Imai, H., Inada, N., Fujimoto, M., Tsutsumi, N., et al. (2009). Functional association of cell death suppressor, Arabidopsis Bax inhibitor-1, with fatty acid 2-hydroxylation through cytochrome b5. Plant J. 58, 122-134. doi: 10.1111/j.1365-313X.2008.03765.x

Nagano, M., Ishikawa, T., Ogawa, Y., Iwabuchi, M., Nakasone, A., Shimamoto, K., et al. (2014). Arabidopsis Bax inhibitor-1 promotes sphingolipid synthesis during cold stress by interacting with ceramide-modifying enzymes. Planta 240, 77-89. doi: $10.1007 / \mathrm{s} 00425-014-2065-7$

Nagano, M., Takahara, K., Fujimoto, M., Tsutsumi, N., Uchimiya, H., and Kawai-Yamada, M. (2012). Arabidopsis sphingolipid fatty acid 2-hydroxylases (AtFAH1 and AtFAH2) are functionally differentiated in fatty acid 2hydroxylation and stress responses. Plant Physiol. 159, 1138-1148. doi: 10.1104/pp.112.199547

Pata, M. O., Hannun, Y. A., and Ng, C. K. (2010). Plant sphingolipids: decoding the enigma of the Sphinx. New Phytol. 185, 611-630. doi: 10.1111/j.14698137.2009.03123.x

Qureshi, M. I., Abdin, M. Z., Ahmad, J., and Iqbal, M. (2013). Effect of long-term salinity on cellular antioxidants, compatible solute and fatty acid profile of Sweet Annie (Artemisia annua L.). Phytochemistry 95, 215-223. doi: 10.1016/j.phytochem.2013.06.026

Raffaele, S., Vailleau, F., Léger, A., Joubès, J., Miersch, O., Huard, C., et al. (2008). A MYB transcription factor regulates very-long chain fatty acid biosynthesis for activation of the hypersensitive cell death response in Arabidopsis. Plant Cell 20, 752-767. doi: 10.1105/tpc.107.054858

Saucedo-García, M., Guevara-García, A., González-Solís, A., Cruz-García, F., Vázquez-Santana, S., Markham, J. E., et al. (2011). MPK6, sphinganine and the LCB2a gene from serine palmitoyltransferase are required in the signaling pathway that mediates cell death induced by long chain bases in Arabidopsis. New Phytol. 191, 943-957. doi: 10.1111/j.1469-8137.2011.03727.x

Sharfman, M., Bar, M., Ehrlich, M., Schuster, S., Melech-Bonfil, S., Ezer, R., et al. (2011). Endosomal signaling of the tomato leucine-rich repeat receptor-like protein LeEix2. Plant J. 68, 413-423. doi: 10.1111/j.1365-313X.2011.04696.x

Shockey, J. M., Gidda, S. K., Chapital, D. C., Kuan, J. C., Dhanoa, P. K., Bland, J. M., et al. (2006). Tung tree DGAT1 and DGAT2 have non redundant functions in triacylglycerol biosynthesis and are localized to different subdomains of the endoplasmic reticulum. Plant Cell 18, 2294-2313. doi: 10.1105/tpc.106. 043695

Simanshu, D. K., Zhai, X., Munch, D., Hofius, D., Markham, J. E., Bielawski, J., et al. (2014). Arabidopsis accelerated cell death 11, ACD11, is a ceramide-1phosphate transfer protein and intermediary regulator of phytoceramide levels. Cell Rep. 6, 388-399. doi: 10.1016/j.celrep.2013.12.023

Stanislas, T., Bouyssie, D., Rossignol, M., Vesa, S., Fromentin, J., Morel, J., et al. (2009). Quantitative proteomics reveals a dynamic association of proteins to detergent-resistant membranes upon elicitor signaling in tobacco. Mol. Cell. Proteomics 8, 2186-2198. doi: 10.1074/mcp.M900090-MCP200

Tanaka, T., Kida, T., Imai, H., Morishige, J., Yamashita, R., Matsuoka, H., et al. (2013). Identification of a sphingolipid-specific phospholipase D activity associated with the generation of phytoceramide-1-phosphate in cabbage leaves. FEBS J. 280, 3797-3809. doi: 10.1111/febs.12374

Teh, O. K., and Hofius, D. (2014). Membrane trafficking and autophagy in pathogen-triggered cell death and immunity. J. Exp. Bot. 65, 1297-1312. doi: $10.1093 / \mathrm{jxb} / \mathrm{ert} 441$

Ternes, P., Feussner, K., Werner, S., Lerche, J., Iven, T., Heilmann, I., et al. (2011). Disruption of the ceramide synthase LOH1 causes spontaneous cell death in Arabidopsis thaliana. New Phytol. 192, 841-854. doi: 10.1111/j.14698137.2011.03852.x

Volmer, R., and Ron, D. (2015). Lipid-dependent regulation of unfolded protein response. Curr. Opin. Cell Biol. 33, 67-73. doi: 10.1016/j.ceb.2014.12.002

Wang, W., Wen, Y., Berkey, R., and Xiao, S. (2009). Specific targeting of the Arabidopsis resistance protein RPW8.2 to the interfacial membrane encasing the fungal haustorium renders broad-spectrum resistance to powdery mildew. Plant Cell 21, 2898-2913. doi: 10.1105/tpc.109.067587 
Wang, W., Yang, X., Tangchaiburana, S., Ndeh, R., Markham, J. E., Tsegaye, Y., et al. (2008). An inositolphosphorylceramide synthase is involved in regulation of plant programmed cell death associated with defense in Arabidopsis. Plant Cell 20, 3163-3179. doi: 10.1105/tpc.108.060053

Xiao, S., and Chye, M. L. (2011). New roles for acyl-CoA-binding proteins (ACBPs) in plant development, stress responses and lipid metabolism. Prog. Lipid Res. 50, 141-151. doi: 10.1016/j.plipres.2010.11.002

Xie, L. J., Yu, L. J., Chen, Q. F., Wang, F. Z., Huang, L., Xia, F. N., et al. (2015). Arabidopsis acyl-CoA-binding protein ACBP3 participates in plant response to hypoxia by modulating very-long-chain fatty acid metabolism. Plant J. 81, 53-67. doi: 10.1111/tpj.12692

Young, M. M., Kester, M., and Wang, H. G. (2013). Sphingolipids: regulators of crosstalk between apoptosis and autophagy. J. Lipid Res. 54, 5-19. doi: 10.1194/jlr.R031278

Yu, Z., Sawkar, A. R., and Kelly, J. W. (2007). Pharmacologic chaperoning as a strategy to treat Gaucher disease. FEBS J. 274, 4944-4950. doi: 10.1111/j.17424658.2007.06042.x
Zemanová, V., Pavlík, M., Kyjaková, P., and Pavlíková, D. (2015). Fatty acid profiles of ecotypes of hyperaccumulator Noccaea caerulescens growing under cadmium stress. J. Plant Physiol. 180, 27-34. doi: 10.1016/j.jplph.2015.02.012

Zhu, X., and Xiong, L. (2013). Putative megaenzyme DWA1 plays essential roles in drought resistance by regulating stress-induced wax deposition in rice. Proc. Natl. Acad. Sci. U.S.A. 110, 17790-17795 doi: 10.1073/pnas.1316412110

Conflict of Interest Statement: The authors declare that the research was conducted in the absence of any commercial or financial relationships that could be construed as a potential conflict of interest.

Copyright $\odot 2016$ De Bigault Du Granrut and Cacas. This is an open-access article distributed under the terms of the Creative Commons Attribution License (CC BY). The use, distribution or reproduction in other forums is permitted, provided the original author(s) or licensor are credited and that the original publication in this journal is cited, in accordance with accepted academic practice. No use, distribution or reproduction is permitted which does not comply with these terms. 